\title{
EFFECT OF SINTERING ATMOSPHERE ON THE PORE-STRUCTURE STABILITY OF CERIUM-DOPED NANOSTRUCTURED ALUMINA
}

\author{
Krishnankutty-Nair P. Kumar" , Janne Tranto ${ }^{a}$, Balagopal N. Nair ${ }^{b}$, Jalajakumari \\ Kumar $^{\mathrm{b}}$, Jacob W. Høj and John E. Engella \\ anstitute of Mineral Industry, Technical University of Denmark, DK-2800 Lyngby, \\ Denmark \\ 'Laboratory for Inorganic Chemistry, Materials Science and Catalysis, Faculty of \\ Chemical Technology, University of Twente, 7500 AE Enschede, The Netherlands
}

(Received December 13, 1993; Refereed)

\section{ABSTRACT}

Pore-structure stability of pure and Ce-doped alumina in air and argon atmospheres was studied using DTA, TGA, $\mathrm{N}_{2}$ ads./des. and XRD with a view to understand the importance of the ionic size of the dopant cation on the porestructure stability of alumina. The ionic size effect was studied by heat treating the Ce-alumina system in both oxidizing and reducing atmospheres to have $\mathrm{Ce}^{4+}(87 \mathrm{pm})$ and $\mathrm{Ce}^{3+}$ (106 pm) respectively. No compound formation between $\mathrm{Ce}$ and alumina was observed. In the case of pure alumina there is a drastic reduction in porosity during the transformation to $\alpha$-alumina. Ce-doped alumina has a higher DSC transformation temperature corresponding to the $\alpha$ alumina transformation compared to pure alumina. Ce-doped alumina showed higher pore-structure stability compared with pure alumina and the stability was relatively higher in reducing atmosphere (higher $\mathrm{Ce}^{3+} / \mathrm{Ce}^{4+}$ ratio, higher effective ionic size) compared with oxidizing conditions (lower $\mathrm{Ce}^{3+} / \mathrm{Ce}^{4+}$ ratio, lower effective ionic size).

MATERIALS INDEX: Alumina, Cerium, Oxides, Boehmite

'Present address: Shell Research BV, Postbus 3003, 1003 AA Amsterdam, The Netherlands. 


\section{INTRODUCTION}

Porous nanostructured materials are finding increasing importance in the fields of separation technology and catalysis [1-18]. One of the major difficulties in using porous nanostructured ceramics is their inherent tendency for surface area and porosity reduction. There is a large volume of literature available on the pore-structure stability of porous alumina [16-25]. It has been noted by many investigators that, in the case of transition aluminas, there is a considerable reduction in surface area during the transformation to $\alpha$-alumina $[18,24]$. The rate of reduction in surface area can be retarded by suitable doping [16-24]. However, the actual mechanism of retardation is not clear yet [16-24]. Ba and rare earth cations are the most studied dopants and their behaviours at high temperatures vary from one another [16-24]. Kato et al. have attributed the stability of lanthanide-doped alumina to the formation of $\beta$-alumina type of structures [24]. However, their results show a regular increase in stability (surface area) with increase in the ionic size of the dopant lanthanide [24]. In a recent study it has been noticed that the DSC transformation temperature corresponding to the transition to $\alpha$-alumina and the stability (retained surface area) increased with increasing ionic size of the dopant cations ( $\mathrm{La}, \mathrm{Nd}$ and $\mathrm{Gd}$ ) studied [18]. The present study has been carried out for understanding the effect of ionic size on the pore-structure stability of Ce-doped alumina.

The major difficulty in studying the effect of ionic size of the dopants is that it is not possible to separate the effect of ionic size from the effects caused by the differences in the compounds formed. Different dopant cations form different types of compounds with alumina. Ce doping offers an advantage in this regard. $\mathrm{CeO}_{2-\mathrm{x}}(\mathrm{x}<3)$ is known to exist in a range of non-stoichiometric compositions [26-28]. The valency of $\mathrm{Ce}$ in $\mathrm{Ce}$-doped alumina can be 3 or 4 depending on the oxidizing or reducing behaviour of the sintering atmosphere and $\mathrm{Ce}^{3+}(106 \mathrm{pm})$ is larger than $\mathrm{Ce}^{4+}(87 \mathrm{pm})$. Moreover, it is expected that the compounds formed at high temperatures will be of the same type irrespective of the valency of $\mathrm{Ce}[27]$.

\section{EXPERIMENTAL}

Pure and doped alumina samples were prepared from a commercial boehmite (A|OOH) sol (NYACOL, Al-20, Nyacol products Inc.) containing approximately 4 moles of $\mathrm{AOOH}$ in $1000 \mathrm{ml}$ of water containing $\mathrm{HNO}_{3}$ with a pH of about 4 . The boehmite primary particles are needle shaped with a diameter in the range of 5 to $10 \mathrm{~nm}$ and length in the range of 15 to $25 \mathrm{~nm}$. Precursor sol for Ce-doped samples were prepared by first diluting the original sols by a factor of two and then adding an aqueous solution of cerium nitrate $\left(\mathrm{Ce}\left(\mathrm{NO}_{3}\right)_{3} \cdot 6 \mathrm{H}_{2} \mathrm{O}\right)$ to the diluted sol to get the final $\mathrm{AlOOH}$ concentration of about 1.33 
mol/l. It is important to dilute the sol before dopant addition to avoid flocculation arising from the sudden increase in the ionic strength [29]. The $\mathrm{Ce}$ concentration was kept at 3 atom\% $(\mathrm{Ce} /(\mathrm{Al}+\mathrm{Ce})=0.03)$. Some pure alumina samples were also made from diluted sols having one-third of the original concentration. This was done to have a perfect comparison with the doped samples, since the precursor sol for the doped sample was diluted by a factor of three. All the samples were calcined at different temperatures for 8 $h$ at a heating rate of either 1.5 or $1.7 \mathrm{~K} / \mathrm{min}$ in a Mettler TGA cell in both air and argon atmosphere. The calcined samples were subjected to XRD step-scan (Philips PW 1710, CuK $\alpha$ radiation, step size $=0.015^{\circ}(2 \theta)$ and counting time of $10 \mathrm{~s}$ ) and $\mathrm{N}_{2}$ physisorption analysis (Micromeritics ASAP 2400). As-dried pure and Ce-doped samples were subjected to DSC and TGA with a heating rate of $20 \mathrm{~K} / \mathrm{min}$ in flowing $\mathrm{O}_{2}$, air or argon.

\section{RESULTS AND DISCUSSION}

The DSC trace of pure boehmite gel (dried at $40^{\circ} \mathrm{C}$ ) performed with a heating rate of 20 $\mathrm{K} / \mathrm{min}$ in flowing air gave two endothermic peaks and one sharp exothermic peak [18]. The first endothermic peak, centred around $90^{\circ} \mathrm{C}$, corresponds to the removal of water present in the pores and it was noticed from the TGA trace that the weight loss was about $5 \%$. The second endothermic peak, centred around $470^{\circ} \mathrm{C}$, may be attributed to the removal of hydroxyl groups and residual nitrates. There was a weight loss of about $18 \%$ associated with this. The nitrates come from the nitric acid used for electrostatically stabilizing the boehmite sol. The sharp exothermic peak around $1240^{\circ} \mathrm{C}$ represents the transformation from transition to $\alpha$-alumina. XRD of samples heated to about $1280^{\circ} \mathrm{C}$, which is well above the temperature corresponding to the completion of the transformation, with a heating rate of $20 \mathrm{~K} / \mathrm{min}$ showed all the peaks corresponding to $\alpha$-alumina. It should be noted that, it was observed from XRD results, samples heated at $1100^{\circ} \mathrm{C}$ (with a heating rate of $1.7 \mathrm{~K} / \mathrm{min}$.) for eight hours convert to more than $95 \% \alpha-$ alumina. This is because of the slow heating rate and long soaking time. It is also important to recall the fact that the transformation to $\alpha$-alumina is a metastable-to-stable transformation. Unlike equilibrium transformations these are not reversible and there is no real equilibrium transformation temperature. The transformation temperature, or the extent of transformation, depends on factors like heating rate and soaking time.

Fig. 1 shows the surface area and porosity reduction of pure alumina calcined at different temperatures for eight hours. There is about $45 \%$ reduction in surface area when the material is calcined from the gel state to $900^{\circ} \mathrm{C}$. After $900^{\circ} \mathrm{C}$, the reduction in surface area is as high as $95 \%$. A drastic reduction in the pore volume can also be seen above $900^{\circ} \mathrm{C}$. It was observed from the XRD results that up to $800^{\circ} \mathrm{C}$ the major phases were transition aluminas (a mixture of $\gamma, \delta$ and $\theta$-aluminas) and by $1100^{\circ} \mathrm{C}$ it converts to more than $95 \%$ 
$\alpha$-alumina. The above results indicate that the surface area and porosity reduction process is enhanced by the phase transformation to $\alpha$-alumina. Up to $900^{\circ} \mathrm{C}$ the pore volume remains more or less the same, whereas the surface area decreases from about 200 to $110 \mathrm{~m}^{2} / \mathrm{g}$ (Fig.1). Surface area reduction without appreciable reduction in porosity

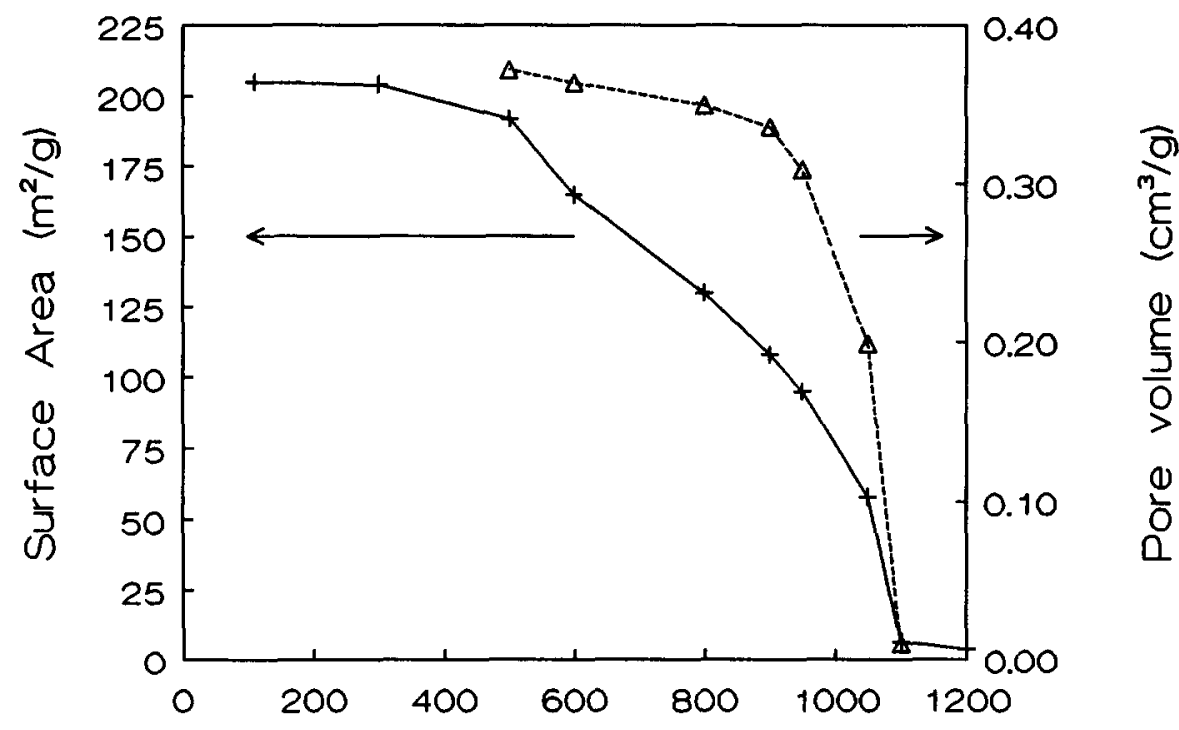

Temperature $\left({ }^{\circ} \mathrm{C}\right)$

FIG.1 Surface area and pore volume of pure alumina with calcination temperature

is a typical example of sintering involving mass transport essentially through surface diffusion. Between 900 and $1100^{\circ} \mathrm{C}$ there is a considerable decrease in both surface area and pore volume (Fig.1) indicating the fact that mass transport mechanisms other than surface diffusion (volume diffusion, grain boundary diffusion etc.) are also operative at that temperature range.

Fig.2 gives typical DSC and TGA traces of Ce-doped alumina gel heated in flowing $\mathrm{N}_{2}$ with a heating rate of $20 \mathrm{~K} / \mathrm{min}$. There are three endothermic peaks in the low temperature side of DSC trace. The first peak centred around $90^{\circ} \mathrm{C}$ represents the removal of water present in the pores of the alumina gel. The second peak, which is around $220^{\circ} \mathrm{C}$, may be attributed to the removal of water present in very small pores (size $<2 \mathrm{~nm}$ ). The peak at around $500^{\circ} \mathrm{C}$ can be attributed to the decomposition of cerium nitrate present in the gel and the dehydroxylation reaction. The TGA trace also shows three weight loss regions corresponding to the endothermic peaks in DSC. The first two weight loss regions can not be distinguished clearly because they are very close to each other (centred around 90 and $220^{\circ} \mathrm{C}$ ). There is a total weight loss of about $30 \%$. The exothermic peak in the DSC at around $1345^{\circ} \mathrm{C}$ corresponds to the transformation to $\alpha$-alumina. 
Table 1 lists the DSC transformation temperature corresponding to the transformation to $\alpha$-alumina for pure and Ce-doped alumina heat treated in different atmospheres with a heating rate of $20 \mathrm{k} / \mathrm{min}$. The temperature corresponding to pure alumina remains the same irrespective of the atmosphere of heat treatment. In the case of Ce-doped alumina the transformation temperature increases with decreasing $\mathrm{O}_{2}$ partial pressure (in qualitative terms). It is reasonable to assume that with decreasing $\mathrm{O}_{2}$ partial pressure the $\mathrm{Ce}^{3+} / \mathrm{Ce}^{4+}$ ratio will increase. This effect was observed from the colour of the samples after heat treatment. The samples heated in $\mathrm{O}_{2}$ and air appeared to be light yellow and the ones heated in argon or $\mathrm{N}_{2}$ looked more blueish. The yellow and blue colours indicate the presence of $\mathrm{Ce}^{4+}$ and $\mathrm{Ce}^{3+}$ respectively. However, more quantitative assessments are

TABLE 1

DSC transformation temperatures $\left({ }^{\circ} \mathrm{C}\right)$ of pure and $\mathrm{Ce}$-doped alumina in different atmospheres

\begin{tabular}{||l|l|l|l|}
\cline { 2 - 4 } \multicolumn{1}{c|}{} & $\mathrm{O}_{2}$ & Air & $\mathrm{Ar} / \mathrm{N}_{2}$ \\
\hline Pure alumina & $1240 \pm 3$ & $1240 \pm 3$ & $1240 \pm 3$ \\
\hline $\begin{array}{l}\text { Ce-doped } \\
\text { alumina }\end{array}$ & $1300 \pm 4$ & $1313 \pm 4$ & $1340 \pm 10$ \\
\hline
\end{tabular}

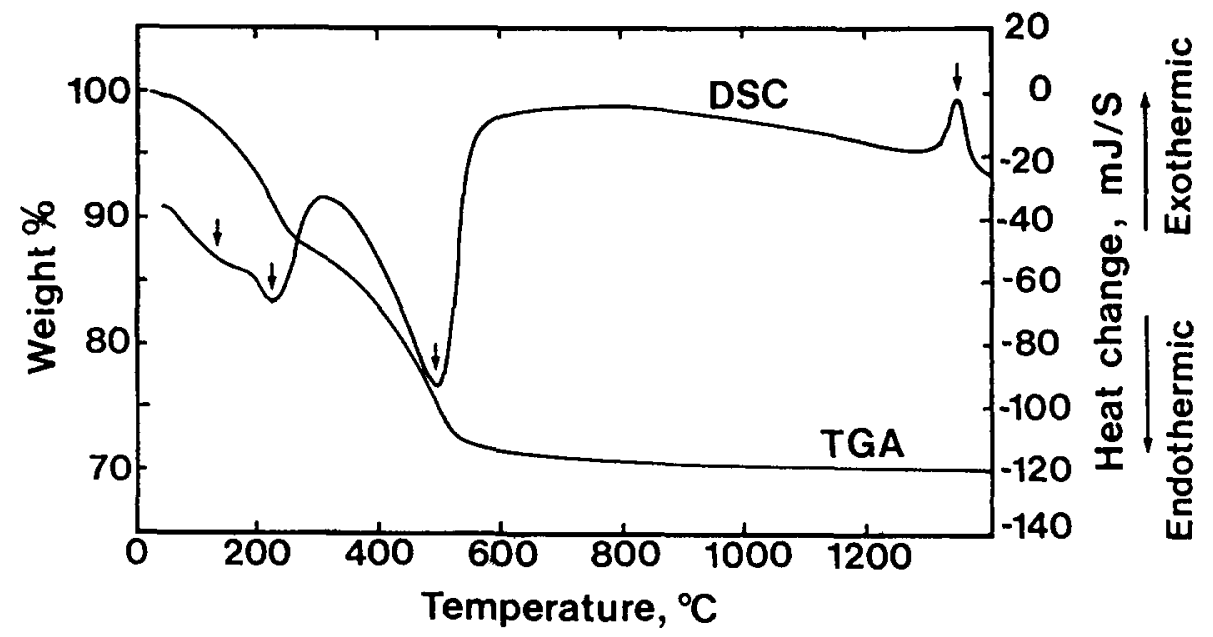

FIG.2 DSC and TGA traces of Ce-doped alumina heated in flowing $\mathrm{N}_{2}$ 
to be made using XPS to find out the exact ratio of $\mathrm{Ce}^{3+} / \mathrm{Ce}^{4+}$.

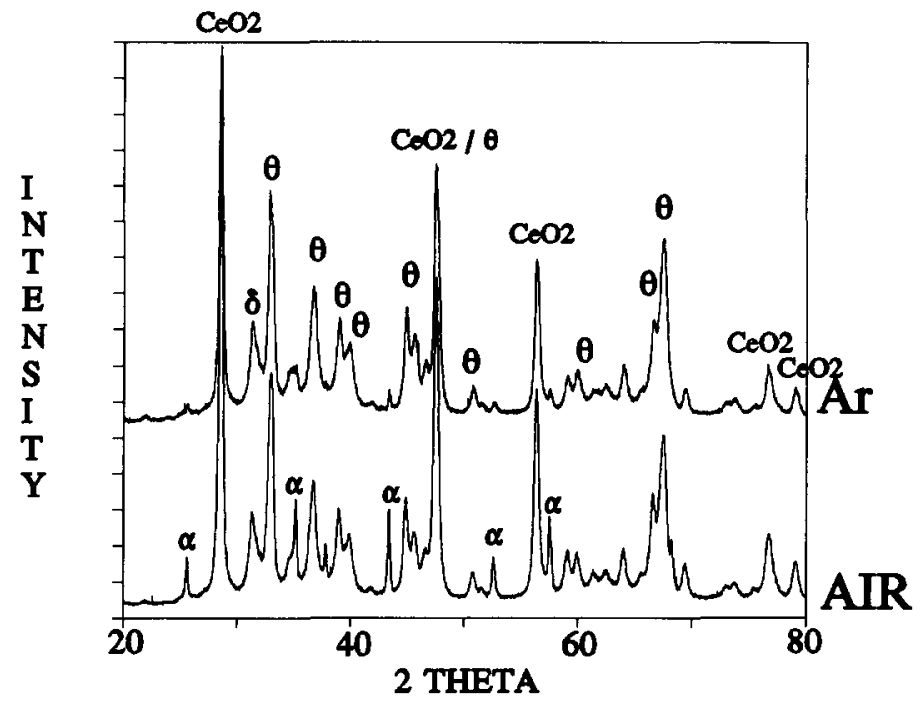

FIG.3 XRD patterns of Ce-doped alumina heated at $1100^{\circ} \mathrm{C}$ for $8 \mathrm{~h}$ in air and argon

From Table 2 it can be seen that, as expected from the DSC phase transformation behaviour, the surface area and porosity of Ce-doped alumina is higher than pure alumina. Ce-doped alumina retained a higher surface area and porosity when calcined in argon compared with air. The textural parameters of pure alumina remains the same irrespective of the atmosphere of calcination. The XRD pattern of $\mathrm{Ce}$-doped alumina calcined at $1100^{\circ} \mathrm{C}$ for $8 \mathrm{~h}$ in air and argon is given in Fig.3. Both the patterns show a mixture of $\mathrm{CeO}_{2-x}$, transition aluminas and a small amount of $\alpha$-alumina. The strong peaks correspond to $\mathrm{CeO}_{2}$ and $\theta$-alumina. It is important to note that both the samples contain the cubic $\mathrm{CeO}_{2-x}$. This is not unexpected because even if there is a slight deviation from the stoichimetric composition, because of the difference in the $\mathrm{Ce}^{3+} / \mathrm{Ce}^{4+}$ ratio between the samples, $\mathrm{CeO}_{2-x}$ will crystallize in the cubic form if $x$ is less than about 0.1 . It should be noted that even though there is only 3 atom\% of $\mathrm{Ce}$ in the sample, the $\mathrm{CeO}_{2}$ peaks are much stronger than the alumina peaks. This may be due to the presence of $\mathrm{CeO}_{2}$ on the surface of alumina particles. In addition, the transition alumina peaks are much weaker compared with the $\mathrm{CeO}_{2}$ peaks. The major difference between the two samples is that the one calcined in air shows relatively larger peaks corresponding to $\alpha$-alumina compared to the sample calcined in argon. This clearly shows that when $\mathrm{Ce}^{3+}$ to $\mathrm{Ce}^{4+}$ ratio (effective ionic size) is increased (more of $\mathrm{Ce}^{3+}$ in argon atmosphere) the transition to $\alpha$-alumina is retarded and the stability is improved. It should be noted that the phase transformation may not be the direct cause of pore-structure instability. But during phase transformation surface area and porosity reduction rate can be enhanced due to the so called Hedvall effect [30]. During any solid state transformation, especially ones imolving nucleation and growth like in the case of $\alpha$-alumina, atoms break bonds and now bonds are created. Moreover, nucleation is a cooperative process involving many atoms and during the 
process the mass transport rate is enhanced. A similar effect has been noticed in the case of anatase to rutile transformation in titania [14].

There may be another reason, which may play a role in surface area and porosity reduction, which is related to the difference in the size between the primary particles of the transforming phase (transition alumina) and the critical nuclei size of the new phase ( $\alpha$-alumina). If the critical nuclei size of the $\alpha$-alumina phase is larger than the particle size of the transition alumina phase, then more than one transition alumina particles should sinter together to form a stable nuclei of $\alpha$-alumina inorder to initiate the transformation process. This can cause a drastic reduction in surface area due to particle growth. However, it is very difficult to verify this possibility experimentally due to the complexity of the phases present before transformation to $\alpha$-alumina.

TABLE 2

Surface area $\left(\mathrm{m}^{2} / \mathrm{g}\right)$ and porosity $\left(\mathrm{cm}^{3} / \mathrm{g}\right)$ values of pure and Ce-doped alumina heated at $1100^{\circ} \mathrm{C}$ for eight hours in different atmospheres with a heating rate of 1.5 $\mathrm{K} / \mathrm{min}$.

\begin{tabular}{||l|l|l|||l|l|}
\cline { 2 - 5 } \multicolumn{1}{c|}{} & \multicolumn{2}{l||}{ Air } & Argon \\
\cline { 2 - 5 } \multicolumn{1}{c|}{} & Surface area & Porosity & Surface area & Porosity \\
\hline Pure Alumina & 5 & 0.0099 & 5 & 0.0098 \\
\hline Ce-alumina & 36 & 0.1349 & 45 & 0.1917 \\
\hline
\end{tabular}

\section{CONCLUSIONS}

In the case of pure alumina a drastic reduction in porosity is observed during the transformation to $\alpha$-alumina. Ce doping effectively retarded the transformation to $\alpha$ alumina and the DSC transformation temperature shifted from about 1240 to $1300{ }^{\circ} \mathrm{C}$ when sintered in oxygen and to $1340^{\circ} \mathrm{C}$ when sintered in argon. As expected from the phase transformation behaviour, Ce-doped nanostructured alumina has higher porestructure stability in reducing conditions compared with the samples calcined in oxidising conditions. This behaviour is attributed to the presence of relatively large amounts of $\mathrm{Ce}^{3+}$ in the samples calcined under reducing conditions.

The above results point to the fact that larger dopant cations will retard the transformation to $\alpha$-alumina, and also the porosity reduction, compared with smaller cations, at least before the transformation to $\alpha$-alumina. Moreover, in the present case the compound $\left(\mathrm{CeO}_{2-x}\right)$ formed is the same in both cases, and does not therefore interfere with our conclusion that ionic size is more important compared with the type of compounds formed.

\section{REFERENCES}

1. Q. Xu and M.A. Anderson, J. Am. Ceram. Soc., 76, 2093 (1993) 
2. S. Komarneni, J. Mater. Chem., 2, 1219 (1992)

3. T. Okubo, M. Watanabe, K. Kusakabe and S. Morooka, J. Mater. Sci., 25, 4822 (1990) 4. R. Roy, Y. Suwa and S. Komarneni, in Science of Ceramic Chemical Processing. pp 247, Ed. by L.L. Hench and D.R. Ulrich. Wiely, New York, 1986.

5. A.F.M.Leenaars, K.Keizer and A.J.Burgraaf, J. Mat. Sci. 19, 1077 (1984)

6. K-N. P. Kumar, K. Keizer and A.J. Burggraaf, J. Mater. Chem., $\underline{3}, 917$ (1993)

7. K-N.P. Kumar, K. Keizer, A.J. Burggraaf, T. Okubo, and H. Nagamoto, J. Mat. Chem., $\underline{3}, 923$ (1993)

8. V.T. Zaspalis, W. van Praag, K. Keizer J.R.H. Ross and A.J. Burggraaf, J. Mat. Sci. 27 1023 (1992)

9. P.D.L. Mercera, J.G. van Ommen, E.B.M. Doesburg, A.J. Burggraaf \& J.R.H. Ross, Applied Catalysis 71, 363 (1991)

10. A. Larbot, J.P. Fabre, C. Guizard and L. Cot, J. Am. Ceram. Soc., 72, 257 (1989).

11. M. Asaeda and L.D. Du, J. Chem. Eng. Japan, 19, 72 (1986)

12. C.J. Brinker, T.L. Ward, R. Sehgal, N.K. Raman, S.L. Hietala, D.M. Smith, D.-W. Hua and T.J. Headley, J. Membrane Sci., 77, 165 (1993)

13. M. Asaeda, L.D. Du and M. Fuji, J. Chem. Eng. Japan, 19, 84 (1986)

14. K-N.P. Kumar, K. Keizer, A.J. Burggraaf, T. Okubo, H. Nagamoto, \& S. Morooka, Nature (london), 358, 48 (1992)

15. R.S.A. de Lange, Ph.D. thesis, University of Twente, 7500 AE Enschede, The Netherlands (1993)

16. Y.S. Lin, K.J. de Vries and A.J. Burggraaf, J. Mater. Sci., 26, 715 (1991)

17. Y.S. Lin and A.J. Burggraaf, J. Am. Ceram. Soc., 1991, 74, 219 (1991)

18. K-N. P. Kumar, Internal Report, IM006/93/DTH, Institute of Mineral Industry, Technical University of Denmark

19. M. Ozawa, M. Kimura and A. Isogai,, J. Mater. sci. Lett., $\underline{9}, 709$ (1990)

20. H. Schaper, Ph.D. thesis, Delft University of Technology, The Netherlands, 1984

21. M. Chai, K. Sekizawa, M. Machida, K. Eguchi and H. Arai, Nippon Seramikkuusu Kyokai Gakujutsu Ronbunshi, 99, 530 (1991)

22. F. Oudet, E. Bordes, P. Courtine, G. Maxant, C. Lambert and J.P. Guerlet, in Catalysis and Automotive Pollution Control, Ed. A. Crucq and A. Frennet, Elsevier Science Publ. (1987)

23. M. Ozawa and M. Kimura, J. Mater. sci. Lett., 9, 291 (1990)

24. A. Kato, H. Yamashita and S. Matsuda, in Successful Design of Catalysts, ed. T. Inui, Elsevier Science Publishers B.V., Amsterdam, (1988)

25. C.J. Brinker and G.W. Scherer, Sol-Gel Science, Academic Press, Inc., New York, (1990)

26. P. Kofstad, Nonstoichiometry, Diffusion, and Electrical Conductivity in Binary Metal Oxides, Wiley-Interscience, New York, (1972), p.276

27a. O. Toft Sørensen, Nonstoichiometric Oxides, Academic Press, New York, (1981)

27b. O. Toft Sørensen, Private communication, (1993)

28. M. Hillert and Bo Jansson, J. Amer. Ceram. Soc., 69, 732 (1986)

29. M.J. Gieselmann and M.A. Anderson, J. Amer. Ceram. Soc., 72, 980 (19989)

30. J.A. Hedvall and P.S. Sjoman, Z. El. Chem., 37, S130 (1931) 